\title{
Waist circumference, waist-to-height ratio and conicity index to evaluate android fat excess in Brazilian children
}

\author{
Mariana De Santis Filgueiras*, Sarah Aparecida Vieira, Poliana Cristina de Almeida \\ Fonseca, Patrícia Feliciano Pereira, Andréia Queiroz Ribeiro, Silvia Eloiza Priore, Sylvia do \\ Carmo Castro Franceschini and Juliana Farias de Novaes \\ Department of Nutrition and Health, Biological Sciences Center, Federal University of Viçosa, CEP 36570-900, \\ Viçosa, MG, Brazil
}

Submitted 1 November 2017: Final revision received 1 August 2018: Accepted 23 August 2018: First published online 8 October 2018

\begin{abstract}
Objective: To evaluate the ability of anthropometric measurements to identify excess android fat and to propose cut-off points for excess central adiposity in children, according to age and sex.

Design: A cross-sectional study with children from a municipality of Minas Gerais, Brazil. Receiver-operating characteristic curve analyses were performed to evaluate waist circumference (WC), waist-to-height ratio (WHtR) and conicity index (C-index) in estimating excess android fat by dual energy X-ray absorptiometry (DXA).

Setting: Viçosa, Minas Gerais, Brazil.

Subjects: Children aged 4-9 years ( $n$ 788).

Results: Overweight prevalence was $29 \cdot 1 \%$ and android fat percentage was higher among girls. All central fat measurements were able to discriminate excess android fat in the age groups evaluated, especially WC and WHtR, with cut-off points showing good sensitivity and specificity overall.

Conclusions: Because these methods are easy to obtain and inexpensive, it is possible to use WC, WHtR and C-index in population surveys to evaluate central obesity. The proposed cut-off points showed satisfactory values of sensitivity and specificity and can be used in epidemiological studies.

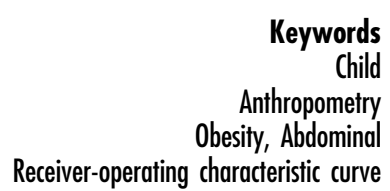

The increasing prevalence of obesity in childhood can be considered a global public health problem, as it is associated with different co-morbidities ${ }^{(1-3)}$. In addition, the distribution of body fat plays an important role in the development of cardiometabolic alterations ${ }^{(4,5)}$

Although the occurrence of central obesity does not necessarily mean a high percentage of body fat ${ }^{(6)}$, it is known that excess visceral fat is related to a worse lipid profile $^{(7-10)}$, high blood pressure ${ }^{(7)}$ and insulin resistance ${ }^{(8)}$ in children and adolescents. Therefore, it is important to evaluate central obesity in childhood through accurate body measurements.

Computed tomography and MRI are reference methods to evaluate central obesity as they estimate the amount of intra-abdominal and subcutaneous fat; however, the high cost and radiation dose delivered by use of computed tomography in children make it difficult to apply these techniques on a large scale ${ }^{(11)}$. Dual-energy X-ray absorptiometry (DXA) is a technique that evaluates central fat in children of all ages, as it estimates the amount of fat in the android and trunk regions ${ }^{(12,13)}$. But again, it is costly and complex, making its use difficult in epidemiological studies and clinical practice, which require low-cost and simple-to-execute methods.

BMI is widely used to identify individuals at cardiometabolic risk, especially in children ${ }^{(14,15)}$. However, this index does not distinguish lean mass from fat mass ${ }^{(16)}$ and it does not allow us to infer about central adiposity, since some studies have shown that children and adolescents classified as lean by BMI have excess fat in the central region ${ }^{(17,18)}$. In this sense, some anthropometric measurements and indices have been proposed, such as waist circumference (WC) and waist-to-height ratio (WHtR), which are simple and low-cost methods to evaluate central obesity and are correlated with cardiometabolic alterations in children ${ }^{(19,20)}$. The conicity index (C-index) has also been gaining importance for its associations with metabolic syndrome in children $^{(21)}$ and alterations in the lipid profile of adolescents $^{(22)}$. It assesses WC in relation to weight and height and assumes that the human body changes from a 
cylindrical shape to a double-cone shape with accumulation of fat in the abdominal region ${ }^{(23)}$.

Because of the wide variety of measures proposed for identifying central obesity in children, it is important to evaluate their performance in estimating central fat compared with reference methods. On the other hand, the lack of consensus on cut-off points for children is a limitation for the routine use of these anthropometric measurements, justifying studies with this theme.

Therefore, the objectives of the present study were to evaluate the ability of anthropometric measurements to discriminate excess android fat in Brazilian children and to propose cut-off points for excess central adiposity, according to age and sex.

\section{Methods}

\section{Population and study design}

The present study was of cross-sectional design and carried out with 788 children aged 4-9 years from the city of Viçosa, Minas Gerais, Brazil. The municipality of Viçosa is located in Zona da Mata Region at $227 \mathrm{~km}$ from the state capital, Belo Horizonte. According to the 2010 Census, Viçosa comprises an area of $299 \mathrm{~km}^{2}$ and 72244 inhabitants, of whom $93.2 \%$ live in urban areas. The gross domestic product per capita in Viçosa was recorded at $\mathrm{R} \$ 7704.50$ in $2014^{(24)}$.

The sample comprising the group aged 4-7 years is part of a retrospective cohort study of children born in the maternity hospital in Viçosa, Minas Gerais, Brazil. The children were selected among the records of infants assisted during the first 6 months of life by the Lactation Support Program (PROLAC), and 669 children were considered eligible for participation. A sample loss of 259 children (38.7\%) was recorded, of whom 176 (26.3\%) were not located (change in address); seventy-five (11.2\%) were not authorized to participate or did not complete all the study stages; and eight (1.2\%) had health problems that prevented participation. Thus the final sample of this age group consisted of 410 children.

Participants of the group aged 8-9 years were selected from the Survey of Health Assessment of Schoolchildren (Pesquisa de Avaliação da Saúde do Escolar - PASE), a cross-sectional population-based study to evaluate the cardiovascular health in children enrolled in urban schools in the municipality of Viçosa, Minas Gerais, Brazil. In 2015, the municipality had seventeen public schools and seven private schools in the urban zone attended by children aged 8 and 9 years, totalling 1464 children enrolled. The Epi Info software (version 7) was used to calculate the sample size of the 8-9 years group, considering the prevalence of obesity of $10.7 \%{ }^{(25)}$, tolerated error of $3 \%$, confidence level at $95 \%$ and $20 \%$ increase to cover losses, making a final sample of 392 children. Stratified random sampling was used to select the students, and the number of children sampled in each school was weighted according to the school size. Next, a draw was carried out using a random number table to complete the number of students needed for each school.

Children under chronic use of medications and with physical, cognitive or multiple disabilities were not included. Once the invitation to participate in the study had been accepted by the parents or guardians, we started data collection at the Health Division of the Federal University of Viçosa.

At the end of the data collection, we recorded $4.2 \%$ of losses due to the non-accomplishment of all stages of the study by some children. The final sample of children aged 8 and 9 years consisted of 378 individuals.

The total sample power of the study ( 788 children), considering the prevalence of $29 \cdot 1 \%$ of overweight children and a $95 \%$ CI, was calculated at $100 \%$.

\section{Anthropometric evaluation}

Data collection was performed in a suitable room by a trained member of the research team, with participants wearing light clothing and no shoes. Weight was measured on a digital electronic scale, with a capacity of $150 \mathrm{~kg}$ and accuracy of $0 \cdot 1 \mathrm{~kg}$. Height was measured using a stadiometer graduated in millimetres, according to Jelliffe ${ }^{(26)}$. Weight and height were measured in duplicate, using their average values.

BMI was calculated using weight and height data. Children's nutritional status was diagnosed according to the WHO $Z$-score recommendation ${ }^{(27,28)}$ adopted by the Brazilian Ministry of Health ${ }^{(29)}$. Overweight and obese children were grouped as overweight.

\section{Central fat measures}

All measures were classified at a later stage, using cut-off points with the best sensitivity and specificity values for android fat, according to age and sex.

WC was measured with an inelastic measuring tape with a $0.1 \mathrm{~cm}$ precision at the level of the umbilical scar. Children remained standing, abdomen relaxed, arms hanging along the body, with their feet joined and body weight supported by both legs ${ }^{(30)}$. WC was measured in duplicate, using the average value of the two measurements. WHtR was calculated by dividing WC (in centimetres) by height (in centimetres) ${ }^{(31)}$. The C-index was calculated from WC (in metres), weight (in kilograms) and height (in metres) using Valdez's formula ${ }^{(23)}$ :

$$
\text { C-index }=\frac{\text { WC }(\mathrm{m})}{0 \cdot 109 \sqrt{\text { weight }(\mathrm{kg}) / \text { height }(\mathrm{m})}} .
$$

\section{Android fat}

Fat in the android region was determined by DXA (Lunar Prodigy Advance; GE Medical Systems Lunar, Milwaukee, WI, USA) using the device software to analyse body composition. The children remained supine on the table and rays were emitted and measured by a discriminant 
energy detector. The children also followed a laboratory protocol for the examination and wore light clothes without any metal ornament.

Android fat comprises the region between the ribs and the pelvis, with the upper limit at $20 \%$ of the distance between the iliac crest and the neck and the lower limit above the pelvis ${ }^{(13)}$. No cut-off points were found for the diagnosis of excess android fat in children in the literature. Therefore, values greater than the 90th percentile of the sample were considered as increased, according to age and sex (girls: 4-5 years, $21 \cdot 6 \%$; $6-7$ years, $28.5 \%$; $8-9$ years, $40.3 \%$; boys: $4-5$ years, $18 \cdot 8 \%$; 6-7 years, $25 \cdot 8 \%$; $8-9$ years, $33 \cdot 8 \%$ ).

\section{Statistical analyses}

Statistical analyses were performed using the statistical software package IBM SPSS Statistics for Windows version 20.0. Variables were tested for normality using the Kolmogorov-Smirnov test.

Descriptive analyses were performed using frequencies (95\% CI) and medians (interquartile range) and comparison of medians between two independent groups by the Mann-Whitney test. Pearson's $\chi^{2}$ test was used to compare the frequencies of WC, WHtR and C-index increased according to sex and overweight. Spearman correlation coefficients were obtained to evaluate the correlation between BMI and other anthropometric measures.

Receiver-operating characteristic curves were constructed to evaluate the ability of central fat measurements to discriminate excess android fat using DXA (>90th percentile). In addition, cut-off points were estimated for excess central fat with the best sensitivity and specificity, positive predictive values and negative predictive values for the different measurements. Hypotheses were tested at $5 \%$ significance level.

\section{Ethical aspects}

The study was approved by the Human Research Ethics Committee of the Federal University of Viçosa (reference numbers 892476/2014 and 663.171/2014). Interviews were carried out only after the participants had been informed of the research objectives and their parents/guardians had signed the Informed Consent Form.

\section{Results}

The sample consisted of $51.7 \%$ boys, and almost $30 \%$ of children in the sample were overweight. The girls had higher percentages of android fat compared with boys (Table 1).

Table 2 shows a high prevalence of overweight children and of increased android fat (31.1\%) and central fat measures (WC: 65.4\%; WHtR: 66.7\%; C-index: 44.7\%). The prevalence of increased android fat (0.9\%) and central fat measures was low in non-overweight children (WC: $2.9 \%$; WHtR: $4.8 \%$; C-index: 5.9\%). Accordingly, BMI showed a direct correlation with WC $(r=0.861, P<0.001)$, WHtR $\quad(r=0.644, \quad P<0.001)$ and C-index $(r=0.401$, $P<0.001$ ) for both sexes (data not shown).

The receiver-operating characteristic curve analysis showed that all measures were able to identify excess android fat in the studied age groups, in both sexes (Table 3 ). Cut-off points of anthropometric measurements capable of estimating excess central fat were identified for each age group and sex. We observed that the WC cut-off ranged from 55.6 to $69.3 \mathrm{~cm}$, that for WHtR from 0.47 to 0.51 and C-index cut-off from 1.21 to 1.29 . In general, sensitivity (62.5 to $100.0 \%)$ and specificity ( 78.2 to $100 \cdot 0 \%$ ) values were satisfactory; however, positive predictive value was low in almost all age groups for the central fat measures evaluated, ranging from $29 \cdot 2$ to $100 \cdot 0 \%$ (Table 4 ).

\section{Discussion}

In the present study, all the anthropometric measurements evaluated were good to identify android fat excess

Table 1 General characteristics of the sample of children aged 4-9 years ( $n$ 788), Viçosa, Minas Gerais, Brazil, 2012/2015

\begin{tabular}{|c|c|c|c|c|c|c|c|}
\hline \multirow[b]{2}{*}{ Variable } & \multicolumn{2}{|c|}{ Total $(n 788)$} & \multicolumn{2}{|c|}{ Girls ( $n$ 381) } & \multicolumn{2}{|c|}{ Boys ( $n$ 407) } & \multirow[b]{2}{*}{$P$ value } \\
\hline & $\begin{array}{c}n \text { or } \\
\text { Median }\end{array}$ & $\%$ or IQR & $\begin{array}{c}n \text { or } \\
\text { Median }\end{array}$ & $\%$ or IQR & $\begin{array}{c}n \text { or } \\
\text { Median }\end{array}$ & $\%$ or IQR & \\
\hline \multicolumn{8}{|l|}{ Age group, $n$ and \% } \\
\hline $4-5$ years & 184 & 23.4 & 80 & $21 \cdot 0$ & 104 & $25 \cdot 6$ & \\
\hline $6-7$ years & 226 & 28.7 & 104 & 23.3 & 122 & 30.0 & \\
\hline $8-9$ years & 378 & 48.0 & 197 & $51 \cdot 7$ & 181 & 44.5 & \\
\hline Income per capita $(R \$)$, median and IQR & 395.00 & $255.00-656.67$ & $400 \cdot 00$ & $250 \cdot 00-656 \cdot 67$ & 393.67 & $255.00-656 \cdot 66$ & 0.872 \\
\hline $\begin{array}{l}\text { Maternal education (years), median and } \\
\text { IQR }\end{array}$ & 11.00 & $8.00-11.00$ & 11.00 & $8.00-11.00$ & 11.00 & $8.00-11.00$ & 0.649 \\
\hline Overweight (\%), $n$ and \% & 229 & $29 \cdot 1$ & 106 & $27 \cdot 8$ & 123 & $30 \cdot 2$ & 0.458 \\
\hline Android fat (\%), median and IQR & $10 \cdot 70$ & $6 \cdot 28-20 \cdot 30$ & 13.55 & $8 \cdot 00-23 \cdot 15$ & 8.45 & $5 \cdot 20-17 \cdot 75$ & $<0.001^{*}$ \\
\hline WC $(\mathrm{cm})$, median and IQR & 56.50 & $53 \cdot 00-62 \cdot 20$ & $56 \cdot 20$ & $52 \cdot 80-63 \cdot 20$ & 56.50 & $53 \cdot 00-61.45$ & 0.854 \\
\hline WHtR, median and IQR & 0.46 & $0.42-0.49$ & 0.46 & $0.42-0.49$ & 0.46 & $0.43-0.49$ & 0.763 \\
\hline C-index, median and IQR & $1 \cdot 17$ & $1 \cdot 13-1.22$ & $1 \cdot 17$ & $1.13-1.22$ & $1 \cdot 17$ & $1 \cdot 13-1.21$ & 0.680 \\
\hline
\end{tabular}

IQR, interquartile range; WC, waist circumference; WHtR, waist-to-height ratio; C-index, conicity index.

${ }^{*} P<0.05$ (Mann-Whitney test). 
Table 2 Prevalence of increased android fat, waist circumference (WC), waist-to-height ratio (WHtR) and conicity index (C-index), according to overweight, in children aged 4-9 years ( $n$ 788), Viçosa, Minas Gerais, Brazil, 2012/2015

\begin{tabular}{|c|c|c|c|c|c|c|c|}
\hline \multirow[b]{3}{*}{ Variable } & \multicolumn{6}{|c|}{ Overweight } & \multirow[b]{3}{*}{$P$ value } \\
\hline & \multicolumn{3}{|c|}{ Yes } & \multicolumn{3}{|c|}{ No } & \\
\hline & $n$ & $\%$ & $95 \mathrm{Cl} \%$ & $n$ & $\%$ & $95 \mathrm{Cl} \%$ & \\
\hline \multicolumn{8}{|l|}{ Android fat } \\
\hline$>90$ th percentile & 71 & $31 \cdot 1$ & $20 \cdot 5,43 \cdot 1$ & 5 & 0.9 & $0.0,1 \cdot 4$ & \multirow[t]{2}{*}{$<0.001^{\star}$} \\
\hline$\leq 90$ th percentile & 157 & $68 \cdot 9$ & $60 \cdot 9,75 \cdot 9$ & 553 & $99 \cdot 1$ & $97 \cdot 9,99 \cdot 7$ & \\
\hline \multicolumn{8}{|l|}{ WC $\dagger$} \\
\hline High & 149 & 65.4 & $56 \cdot 9,72 \cdot 7$ & 16 & 2.9 & $0.0,20 \cdot 6$ & \multirow{2}{*}{$<0.001^{\star}$} \\
\hline Normal & 79 & $34 \cdot 6$ & $23 \cdot 9,45 \cdot 7$ & 540 & $97 \cdot 1$ & $95 \cdot 2,98 \cdot 3$ & \\
\hline \multicolumn{8}{|l|}{ WHtR† } \\
\hline High & 152 & $66 \cdot 7$ & $58 \cdot 3,73 \cdot 9$ & 27 & $4 \cdot 8$ & $0.1,19.0$ & \multirow[t]{2}{*}{$<0.001^{*}$} \\
\hline Normal & 76 & 33.3 & $22 \cdot 5,44 \cdot 6$ & 531 & $95 \cdot 2$ & $93 \cdot 1,96 \cdot 3$ & \\
\hline \multicolumn{8}{|l|}{ C-index† } \\
\hline High & 102 & $44 \cdot 7$ & $35 \cdot 2,55 \cdot 3$ & 33 & 5.9 & $0.7,20 \cdot 2$ & \multirow[t]{2}{*}{$<0.001^{\star}$} \\
\hline Normal & 126 & $55 \cdot 3$ & $46 \cdot 4,64 \cdot 4$ & 523 & $94 \cdot 1$ & $91 \cdot 7,95.9$ & \\
\hline
\end{tabular}

${ }^{*} P<0.05$ (Pearson's $X^{2}$ test)

†Classification according to the cut-off points proposed in the present study.

estimated by DXA. WC and WHtR stood out in identifying excess android fat.

A key strength of the study is the representative sample size, comprising a wide age range in childhood. Cut-off points and indices of anthropometric measurements were proposed for excess central adiposity in relation to android fat (reference method) in children, according to age and sex, allowing their utilization in other Brazilian studies.

Android fat (central) includes intra-abdominal adipose tissue, which is more lipolytic compared with fat stored in the gynoid region (peripheral), increasing TAG concentrations and the release of fatty acids into the portal circulation. Furthermore, increased liver clearance of fatty acids may stimulate hepatic gluconeogenesis, LDLcholesterol secretion and inhibit hepatic insulin clearance, causing hyperinsulinaemia and insulin resistance ${ }^{(32)}$. Studies with children have shown that a high ratio of android fat to gynoid fat is associated with the worst cardiometabolic profile $\mathrm{s}^{(33,34)}$.

We found that girls in the current study had higher percentages of android fat as measured by DXA. It is known in adults that men are more prone to accumulation of visceral fat than women ${ }^{(35)}$. Nevertheless, a different profile has been observed in children and a study with the age group of 3-10 years, in Santos, São Paulo, Brazil showed that girls are about four times more likely to accumulate fat in the central region of the body ${ }^{(36)}$. At the end of childhood and the beginning of adolescence, we can observe greater differences due to physiological changes, in which the girls accumulate greater adipose tissue mass whereas boys have a greater gain of lean mass ${ }^{(37)}$. However, a study with children aged $3-8$ years in New Zealand showed that even before puberty there is a difference in body composition between sexes, with girls showing approximately $50 \%$ more body fat than boys $(20.4 v \cdot 13 \cdot 5 \% \text {, respectively })^{(38)}$.
The prevalence of central obesity estimated by all measures was higher in overweight children. It is interesting that a Spanish study also found high prevalence of increased WC and WHtR in children and adolescents, even among those classified as normal ${ }^{(17)}$. Such results have demonstrated that BMI has limitations, such as it does not discriminate the location of body fat, and that WC and WHtR are complementary methods which can provide information to identify the cardiometabolic risk.

WC is an easy-to-execute, low-cost, well-established and widely used measure for assessing the health status of adults because it has specific cut-off points according to $\operatorname{sex}^{(39)}$. Its routine use in the paediatric population is still controversial, since there is no consensus on cut-off points for this age group ${ }^{(40,41)}$. Therefore, the importance of the present study regarding the proposed WC cut-off points for children is justified because it is a good measure to identify trunk fat ${ }^{(11)}$, besides being associated with cardiometabolic risk ${ }^{(42)}$.

As was the case with WC, WHtR stood out in identifying central obesity in the Brazilian children assessed in the present study. WHtR is considered good to discriminate central obesity in different age groups because it has a single cut-off, regardless of sex and age ${ }^{(43)}$, and it assumes that there is an acceptable amount of fat in the trunk region for a certain height ${ }^{(44)}$. Studies that evaluated the association between WHtR and cardiometabolic risk in adults proposed 0.50 to be the cut-off point, which is similar to what we propose herein for both sexes, highlighting that its application in the paediatric population is plausible because it has a weak association with age ${ }^{(31)}$.

$\mathrm{C}$-index has been identified as an important parameter in the evaluation of body fat distribution in the paediatric population $^{(45)}$. Although it has performed satisfactorily in the identification of android fat in children, its routine use may be hampered by the lack of specific cut-off points. The cut-off points that we have proposed in the current 


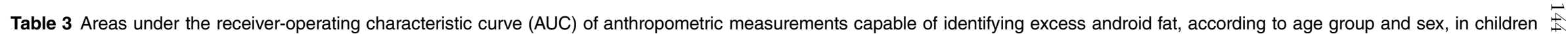
aged $4-9$ years ( $n$ 788), Viçosa, Minas Gerais, Brazil, 2012/2015

\begin{tabular}{|c|c|c|c|c|c|c|c|c|c|}
\hline \multirow[b]{2}{*}{ Variable } & \multicolumn{3}{|c|}{ Total } & \multicolumn{3}{|c|}{ Girls } & \multicolumn{3}{|c|}{ Boys } \\
\hline & AUC & $95 \mathrm{Cl} \%$ & $P$ value & AUC & $95 \mathrm{Cl} \%$ & $P$ value & AUC & $95 \mathrm{Cl} \%$ & $P$ value \\
\hline \multicolumn{10}{|l|}{ WC } \\
\hline $4-5$ years & 0.916 & $0.829,1.000$ & $<0.001^{*}$ & 0.967 & $0.899,0.993$ & $<0.001^{*}$ & 0.877 & $0.796,0.934$ & $<0.001^{*}$ \\
\hline $6-7$ years & 0.925 & $0.849,1.000$ & $<0.001^{*}$ & 0.867 & $0.786,0.926$ & $<0.001^{\star}$ & 0.975 & $0.930,0.995$ & $<0.001^{*}$ \\
\hline $8-9$ years & 0.944 & $0.919,0.970$ & $<0.001^{*}$ & 0.937 & $0.893,0.966$ & $<0.001^{*}$ & 0.953 & $0.912,0.979$ & $<0.001^{*}$ \\
\hline \multicolumn{10}{|l|}{ WHtR } \\
\hline 4-5 years & 0.898 & $0.816,0.979$ & $<0.001^{*}$ & 0.902 & $0.815,0.957$ & $<0.001^{*}$ & 0.904 & $0.830,0.954$ & $<0.001^{*}$ \\
\hline $6-7$ years & 0.915 & $0.824,1.000$ & $<0.001^{*}$ & 0.835 & $0.749,0.900$ & $<0.001^{*}$ & 0.980 & $0.937,0.997$ & $<0.001^{*}$ \\
\hline $8-9$ years & 0.950 & $0.926,0.974$ & $<0.001^{*}$ & 0.937 & $0.893,0.966$ & $<0.001^{*}$ & 0.963 & $0.924,0.985$ & $<0.001^{*}$ \\
\hline \multicolumn{10}{|l|}{ C-index } \\
\hline 4-5 years & 0.803 & $0.737,0.858$ & $<0.001^{*}$ & 0.828 & $0.727,0.903$ & $<0.001^{\star}$ & 0.792 & $0.700,0.866$ & $<0.001^{*}$ \\
\hline $6-7$ years & 0.897 & $0.849,0.933$ & $<0.001^{*}$ & 0.837 & $0.751,0.902$ & $<0.001^{\star}$ & 0.953 & $0.898,0.983$ & $<0.001^{*}$ \\
\hline $8-9$ years & 0.886 & $0.850,0.916$ & $<0.001^{*}$ & 0.885 & $0.831,0.926$ & $<0.001^{*}$ & 0.892 & $0.837,0.933$ & $<0.001^{*}$ \\
\hline
\end{tabular}

WC, waist circumference; WHtR, waist-to-height ratio; C-index: conicity index.

${ }^{*} P<0.05$.

Table 4 Cut-off points, sensitivity (Sens.), specificity (Spec.), positive predictive value (PPV) and negative predictive value (NPV) of anthropometric measurements for identifying excess android fat, according to age group and sex, in children aged $4-9$ years $(n 788)$, Viçosa, Minas Gerais, Brazil, 2012/2015

\begin{tabular}{|c|c|c|c|c|c|c|c|c|c|c|c|c|c|c|}
\hline \multirow[b]{2}{*}{ Variable } & \multicolumn{7}{|c|}{ Girls } & \multicolumn{7}{|c|}{ Boys } \\
\hline & Cut-off point & Sens. (\%) & $95 \% \mathrm{Cl}$ & Spec. (\%) & $95 \% \mathrm{Cl}$ & PPV (\%) & NPV (\%) & Cut-off point & Sens. (\%) & $95 \% \mathrm{Cl}$ & Spec. (\%) & $95 \% \mathrm{Cl}$ & PPV (\%) & NPV (\%) \\
\hline \multicolumn{15}{|l|}{ WC } \\
\hline $4-5$ years & 55.6 & $100 \cdot 0$ & $62 \cdot 9,100 \cdot 0$ & 83.1 & $72 \cdot 3,90 \cdot 9$ & 40.0 & $100 \cdot 0$ & 60.9 & $70 \cdot 0$ & $34 \cdot 8,93 \cdot 0$ & 98.9 & $93.9,99.8$ & 87.5 & $96 \cdot 7$ \\
\hline $6-7$ years & $69 \cdot 3$ & 70.0 & $34.8,93.0$ & $100 \cdot 0$ & $96 \cdot 1,100 \cdot 0$ & $100 \cdot 0$ & 96.9 & 64.4 & $100 \cdot 0$ & $73 \cdot 4,100 \cdot 0$ & 92.7 & $86 \cdot 2,96 \cdot 8$ & $60 \cdot 0$ & $100 \cdot 0$ \\
\hline 8-9 years & $68 \cdot 8$ & 100.0 & $81 \cdot 3,100 \cdot 0$ & 80.5 & $73.9,86.0$ & 34.0 & 100.0 & 65.0 & 100.0 & $81 \cdot 3,100 \cdot 0$ & $79 \cdot 8$ & $72 \cdot 8,85 \cdot 6$ & $35 \cdot 3$ & $100 \cdot 0$ \\
\hline \multicolumn{15}{|l|}{ WHtR } \\
\hline $4-5$ years & 0.50 & 87.5 & $47.4,97.9$ & 87.5 & $77 \cdot 6,94 \cdot 1$ & 43.8 & 98.4 & 0.51 & 90.0 & $55 \cdot 5,98 \cdot 3$ & 89.1 & $80 \cdot 9,94.7$ & 47.4 & 98.8 \\
\hline $6-7$ years & 0.50 & 80.0 & $44.4,96 \cdot 9$ & $86 \cdot 2$ & $77.5,92 \cdot 4$ & 38.1 & 97.6 & 0.51 & $100 \cdot 0$ & $73 \cdot 4,100 \cdot 0$ & 91.8 & $85 \cdot 0,96 \cdot 2$ & $57 \cdot 1$ & $100 \cdot 0$ \\
\hline $8-9$ years & 0.47 & 100.0 & $81 \cdot 3,100 \cdot 0$ & 78.2 & $71.4,84.0$ & 31.6 & $100 \cdot 0$ & 0.49 & 94.4 & $72 \cdot 6,99 \cdot 1$ & 90.8 & $85 \cdot 3,94 \cdot 8$ & 53.1 & 99.3 \\
\hline \multicolumn{15}{|l|}{ C-index } \\
\hline $4-5$ years & 1.25 & 62.5 & $24.7,91.0$ & $95 \cdot 8$ & $88.3,99 \cdot 1$ & 62.5 & $95 \cdot 8$ & 1.21 & $70 \cdot 0$ & $34.8,93.0$ & 81.3 & $71 \cdot 8,88 \cdot 7$ & 29.2 & $96 \cdot 1$ \\
\hline $6-7$ years & 1.29 & 70.0 & $34.8,93.0$ & 98.9 & $94.1,99.8$ & 87.5 & 95.8 & 1.24 & 91.7 & $61.5,98 \cdot 6$ & 91.8 & $85.0,96 \cdot 2$ & 55.0 & 99.0 \\
\hline $8-9$ years & 1.23 & 83.3 & $58.6,96.2$ & 87.7 & $82.0,92 \cdot 1$ & 40.5 & 98.1 & 1.21 & 83.3 & $58.6,96.2$ & 85.9 & $79.6,90 \cdot 8$ & 39.5 & 97.9 \\
\hline
\end{tabular}


study can therefore be applied to epidemiological research with children and it is prudent to evaluate their sensitivity and specificity values for each population.

The receiver-operating characteristic curve analysis allowed for the determination of cut-off points for the measures that identify excess android fat, according to age group and sex. In general, we suggest that these cut-off points can be used in epidemiological studies because they present satisfactory sensitivity and specificity. On the other hand, at ambulatory level they should be used with caution, considering that the positive predictive values were low for most age groups, which would result in false positives; that is, children would be diagnosed with excess central fat when they actually present no such alteration.

Three main strengths of the present study should be highlighted. First, it is one of the few studies proposing cut-off points for excess central adiposity using WC, WHtR and C-index in childhood, and the first carried out with children from Southeastern Brazil. Second, the anthropometric evaluation was performed by a single examiner, which reduced measurement errors. Third, android fat was obtained by a reference method (DXA) and is strongly correlated to intra-abdominal fat in children ${ }^{(39)}$. The study findings contribute to the establishment of cut-off points for anthropometric measurements to estimate excess central adiposity in Brazilian children, since there is no national consensus for the child population. We suggest that studies be done using the cut-off points presented here to validate them for other populations, as well as to evaluate different cardiometabolic outcomes.

Assessing the accuracy of anthropometric measurements to estimate central fat is fundamental, since obesity and associated co-morbidities are increasingly prevalent in childhood, and the adipose tissue being an endocrine organ that secretes different proteins and adipokines involved in cardiometabolic alterations. Epidemiological studies are essential to support the development of public health policies appropriate to the reality of the child population, aiming at the improvement of protocols for assessing body composition.

The present study results allow us to conclude that WC, WHtR and C-index are good to estimate excess android fat in Brazilian children, and it would be useful to include these measures in population studies. The proposed cutoff points can help scientific research in other Brazilian studies.

\section{Acknowledgements}

Acknowledgements: The authors thank the National Council for Scientific and Technological Development (CNPq) and the Foundation for Research Support of the State of Minas Gerais (FAPEMIG) for the financial support; the Coordination for the Improvement of Higher Education Personnel (CAPES) for granting a scholarship; and the children, parents and guardians for participating in the study. Financial support: This work was supported by CNPq (grant numbers 478910/2013-4 and 485124/2011-4) and FAPEMIG (grant number 02055-13). CNPq and FAPEMIG had no role in the design, analysis or writing of this article. Conflict of interest: The authors declare no conflict of interest. Authorship: M.S.F. assisted the conception and design of this work, assisted the data collection, analysis and interpretation of the data, conducted the literature search, as well as wrote the manuscript. S.A.V. and P.C.A.F. assisted the conception and design of this work, assisted the data collection, analysis and interpretation, as well as revised and approved the final version to be published. P.F.P., A.Q.R. and S.E.P. revised and approved the final version to be published. S.C.C.F. and J.F.N. designed the study including the data collection, coordinated and supervised and approved the final version to be published. Ethics of human subject participation: This study was conducted according to the guidelines laid down in the Declaration of Helsinki and all procedures involving human subjects were approved by the Ethics Committee on Human Research of the Federal University of Viçosa (case numbers 892476/2014 and 663.171/2014). Moreover, this project was presented to the Municipal Department of Education, the Regional Superintendent of Education and principals of schools. All participants, as well as their responsible adults, were informed about the objectives of the research and informed consent was obtained from all children's parents/guardians.

\section{References}

1. Freedman DS, Dietz WH, Srinivasan SS et al. (1999) The relation of overweight to cardiovascular risk factors among children and adolescents: the Bogalusa Heart Study. Pediatrics 103, 1175-1182.

2. Juonala M, Magnussen CG, Berenson GS et al. (2011) Childhood adiposity, adult adiposity, and cardiovascular risk factors. $N$ Engl J Med 365, 1876-1885.

3. Savva SC, Tornaritis M, Savva ME et al. (2000) Waist circumference and waist-to-height ratio are better predictors of cardiovascular disease risk factors in children than body mass index. Int J Obes Relat Metab Disord 24, 1453-1458.

4. Chiarelli F \& Marcovecchio ML (2008) Insulin resistance and obesity in childhood. Eur J Endocrinol 159, Suppl. 1, S67-S74.

5. Sjöström CD, Håkangård AC, Lissner L et al. (1995) Body compartment and subcutaneous adipose tissue distributionrisk factor patterns in obese subjects. Obes Res 3, 9-22.

6. Goran MI, Gower BA, Treuth M et al. (1998) Prediction of intra-abdominal and subcutaneous abdominal adipose tissue in healthy prepubertal children. Int J Obes Relat Metab Disord 22, 549-558.

7. Daniels SR, Morrison JA, Sprecher DL et al. (1999) Association of body fat distribution and cardiovascular risk factors in children and adolescents. Circulation 99, $541-545$

8. Freedman DS, Serdula MK, Srinivasan SR et al. (1999) Relation of circumferences and skinfold thicknesses to lipid and insulin concentrations in children and adolescents: the Bogalusa Heart study. Am J Clin Nutr 69, 308-317. 
9. Gillum RF (1999) Distribution of waist-to-hip ratio, other indices of body fat distribution and obesity and associations with HDL cholesterol in children and young adults ages 419 years: the Third National Health and Nutrition Examination Survey. Int J Obes Relat Metab Disord 23, 556563.

10. Gower BA, Nagy TR \& Goran MI (1999) Visceral fat, insulin sensitivity and lipids in prepubertal children. Diabetes $\mathbf{4 8}$, $1515-1521$.

11. Taylor RW, Jones IE, Williams SM et al. (2000) Evaluation of waist circumference, waist-to-hip ratio, and the conicity index as screening tools for high trunk fat mass, as measured by dual-energy X-ray absorptiometry, in children aged 3-19 y. Am J Clin Nutr 72, 490-495.

12. Goulding A, Taylor RW, Gold E et al. (1996) Regional body fat distribution in relation to pubertal stage: a dual-energy X-ray absorptiometry study of New Zealand girls and young women. Am J Clin Nutr 64, 546-551.

13. Mazess RB, Barden HS \& Hanson J (1990) Dual-energy X-ray absorptiometry for total body and regional bonemineral and soft-tissue composition. Am J Clin Nutr 51, 1106-1112.

14. Redondo O, Villamor E, Valdés J et al. (2015) Validation of a BMI cut-off point to predict an adverse cardiometabolic profile with adiposity measurements by dual-energy X-ray absorptiometry in Guatemalan children. Public Health Nutr 18, 951-958.

15. Ogden CL, Carroll MD, Kit BK et al. (2012) Prevalence of obesity and trends in body mass index among US children and adolescents, 1999-2010. JAMA 307, 483-490.

16. Shah NR \& Braverman ER (2012) Measuring adiposity in patients: the utility of body mass index (BMI), percent body fat, and leptin. PLoS One 7, e33308.

17. Schroder H, Ribas L, Koebnick C et al. (2014) Prevalence of abdominal obesity in Spanish children and adolescents. Do we need waist circumference measurements in pediatric practice? PLoS One 9 , e87549.

18. Pereira PF, Serrano HMS, Carvalho GQ et al. (2015) Measurements of body fat distribution: assessment of collinearity with body mass, adiposity and height in female adolescents. Rev Paul Pediatr 33, 63-71.

19. Blüher S, Molz E, Wiegand S et al.; Adiposity Patients Registry Initiative and German Competence Net Obesity (2013) Body mass index, waist circumference, and waist-to-height ratio as predictors of cardiometabolic risk in childhood obesity depending on pubertal development. J Clin Endocrinol Metab 98, 3384-3393.

20. Gröber-Grätz D, Widhalm K, de Zwaan M et al. (2013) Body mass index or waist circumference: which is the better predictor for hypertension and dyslipidemia in overweight/ obese children and adolescents? Association of cardiovascular risk related to body mass index or waist circumference. Horm Res Paediatr 80, 170-178.

21. Andaki ACR, Tinôco ALA, Mendes EL et al. (2014) Anthropometry and physical activity level in the prediction of metabolic syndrome in children. Public Health Nutr 17, 2287-2294.

22. Neta ACPA, Farias Júnior JC, Martins PR et al. (2017) Índice de conicidade como preditor de alterações no perfil lipídico em adolescentes de uma cidade do Nordeste do Brasil. Cad Saude Publica 33, e00029316.

23. Valdez R (1991) A simple model-based index of abdominal adiposity. J Clin Epidemiol 44, 955-956.

24. Instituto Brasileiro de Geografia e Estatística (2010) Censo cidades. http://www.ibge.gov.br/cidadesat/topwindow. htm?1 (accessed August 2014)

25. Novaes JF, Priore SE, Franceschini SCC et al. (2013) Does the body mass index reflect cardiovascular risk factors in Brazilian children? J Trop Pediatr 59, 43-48.
26. Jelliffe DB (1968) Evaluación del Estado de Nutrición de la Comunidad. OMS Série Monografias no. 53. Ginebra: Organización Mundial de Salud.

27. World Health Organization (2006) The WHO Child Growth Standards. Geneva: WHO.

28. World Health Organization (2007) Growth Reference Data for 5-19 Years. Geneva: WHO.

29. Brasil, Ministério da Saúde (2009) Sistema de Vigilância Alimentar e Nutricional (Sisvan): Classificação do Estado Nutricional. http://189.28.128.100/nutricao/docs/geral/sis van_norma_tecnica_criancas.pdf (accessed December 2015)

30. Lohman TG, Roche AF \& Martorell R (1988) Anthropometric Standardization Reference Manual. Champaign, IL: Human Kinetics Books.

31. Ashwell M \& Hsieh SD (2005) Six reasons why the waist-toheight ratio is a rapid and effective global indicator for health risks of obesity and how its use could simplify the international public health message on obesity. Int J Food Sci Nutr 56, 303-307.

32. Björntorp P (1992) Abdominal fat distribution and the metabolic syndrome. J Cardiovasc Pharmacol 20, 526-528.

33. Samsell L, Regier M, Walton C et al. (2014) Importance of android/gynoid fat ratio in predicting metabolic and cardiovascular disease risk in normal weight as well as overweight and obese children. J Obes 2014, 846578.

34. Aucouturier J, Meyer M, Thivel D et al. (2009) Effect of android to gynoid fat ratio on insulin resistance in obese youth. Arch Pediatr Adolesc 163, 826-831.

35. Kuk JL, Lee S, Heymsfield SB et al. (2005) Waist circumference and abdominal adipose tissue distribution: influence of age and sex. Am J Clin Nutr 81, 1330-1334.

36. Melzer MRTF, Magrini IM, Domene SMA et al. (2015) Factors associated with abdominal obesity in children. Rev Paul Pediatr 33, 437-444.

37. Frignani RR, Passos MAZ, Ferrari GLM et al. (2015) Reference curves of the body fat index in adolescents and their association with anthropometric variables. J Pediatr (Rio J) 91, 248-255.

38. Taylor RW, Gold E, Manning P et al. (1997) Gender differences in body fat content are present well before puberty. Int J Obes Relat Metab Disord 21, 1082-1084.

39. Lean ME, Han TS \& Morrison CE (1995) Waist circumference as a measure for indicating need for weight management. BMJ 311, 158-161.

40. Fernández JR, Redden DT, Pietrobelli A et al. (2004) Waist circumference percentiles in nationally representative samples of African-American, European-American, and Mexican-American children and adolescents. J Pediatr 145 , 439-444.

41. McCarthy HD, Jarrett KV \& Crawley HF (2001) The development of waist circumference percentiles in British children aged 5.0-16.9 y. Eur J Clin Nutr 55, 902-907.

42. Sardinha LB, Santos DA, Silva AM et al. (2016) A comparison between BMI, waist circumference, and waist-to-height ratio for identifying cardio-metabolic risk in children and adolescents. PLoS One 11, e0149351.

43. Li C, Ford ES, Mokdad AH et al. (2006) Recent trends in waist circumference and waist-height ratio among US children and adolescents. Pediatrics 118, e1390-e1398.

44. McCarthy HD \& Ashwell M (2006) A study of central fatness using waist-to-height ratios in UK children and adolescents over two decades supports the simple message - 'keep your waist circumference to less than half your height'. Int J Obes (Lond) 30, 988-992.

45. Pérez B, Landaeta-Jimenez M \& Vasquez M (2002) Fat distribution in Venezuelan children and adolescents estimated by the conicity index and waist/hip ratio. Am J Hum Biol 14, 15-20. 